Original Article

\title{
A CROSS SECTIONAL STUDY TO MEASURE PATIENTS' PERCEPTION OF QUALITY OF NURSING CARE AT MEDICAL WARDS
}

\author{
A. Tamilselvi ${ }^{1} \&$ Rajee Reghunath ${ }^{2}$ \\ ${ }^{1}$ HOD, Department of M edical Surgical Nursing, P.S.G. College of Nursing, Coimbatore, \\ ${ }^{2}$ Principal, Amla College of Nursing, Trissur \\ Correspondence \\ A. Tamilselvi \\ ${ }^{1}$ HOD, Department of Medical Surgical Nursing, P.S.G. College of Nursing, Coimbatore \\ E-mail : selvitamil2k4@yahoo.co.uk
}

\begin{abstract}
:
Traditionally quality of care has been measured against expectations of health professionals and standards rather than being grounded in the perspectives of patients. The most important aspect on which patients' perspective on quality of care depends is "nursing care" because nurses are involved in every aspect of patients' care in hospital. Thus, it is important to measure patients' perception of quality of nursing care in medical wards. A cross sectional descriptive study design was used and total of 50 patients recruited for the study by using purposive sampling technique. Patients' satisfaction with nursing care quality (PSNCQQ) questionnaire was used to measure the patients' perception of quality of nursing care after obtaining reliability. The results revealed that $34 \%$ of patients were between the age group of 21-40 years and half of them were males. The total mean score of patients' perception of quality of nursing care was 64.8 with standard deviation of (+) or (-) 13.2 and 40 patients' (80\%) perceived overall aspect of quality of nursing care. There were $19(38 \%)$ perceived low quality in the dimensions of providing information and skill and competency. This was supported by the results of the study revealed that almost 1/3 patients (31.6\%) perceived that nurses did not offer adequate "explanation and information" about their treatment in hospital and home care and follow up advice. Thus, it was concluded that nurses need to improve their skill and competency and update their knowledge by attending continuing nursing education program and skill training workshops
\end{abstract}

Keywords: patients' perception, quality of nursing care, medical wards

\section{Introduction:}

Globally, health care industry has changed and grown and quality of health care is being recognized as a right rather than privilege. ${ }^{1}$ The overall goal stated by the World Health Organization (WHO) and the international council of nurses (ICN) is the highest possible level of health for all people, ${ }^{2}$ and providing high quality care is one approach for reaching this goal. M easuring quality of care in the health care organization has become very important aspect in evaluating health care services. ${ }^{3}$

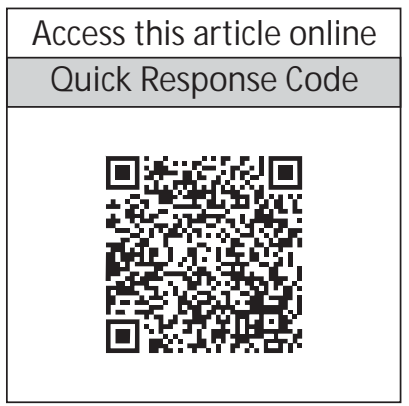

Traditionally, quality of care has been measured against expectations of health professionals and standards rather than being grounded in the views of patients.
${ }^{4}$ Recently, the criteria for evaluating the performance of the health care system was developed by the U.S. National Centre for health services research and department (NCHSRD, 1970) includedthree categories such as mortality, morbidity and patients' perspective. Among these three, patients' perspective is probably the most difficult aspect to measure, but it is very important in determining quality of care ${ }^{3}$ and cannot be set aside.

The most important aspect on which patients' perspective on quality of care depends is "nursing care" because nurses are involved in every aspect of patients' care in hospital. ${ }^{1}$ Nowadays health care organizations are more concerned about quality of nursing care and each health care industry is accountable to its patients. Consumers expect value for their money and count on the quality of services when needed. As valiant effort and marsh emphasize, patients now complain, demand, report and sue and have realized 
that quality of nursing care is an important factor in patient outcome. ${ }^{1}$

Thus, it is important to measure patients' perception of quality of nursing care in medical wards of a selected hospital.

\section{Statement of the Problem:}

A cross sectional study to measure the patients' perception of quality of nursing care in medical wards at a selected hospital.

\section{Objectives:}

I Measure the patients' perception of quality of nursing care in various dimensions

I Identify the overall patients' perception of quality of nursing care in medical wards.

I Association between patients' length of stay and their perception of quality of nursing care.

\section{Materials and Methods:}

A cross sectional descriptive study design was used to measure patients' perception of quality of nursing care in medical wards of a selected hospital. Total of 50 patients recruited for the study by using purposive sampling technique, based on inclusion criteria such as adult medical patients aged 18 years or older, who have spent at least 3 days or more in the ward, able to understand Tamil or English and agreed to participate in this study and signed informed consent, and selected patients were interviewed.

Patients' satisfaction with nursing care quality (PSNCQQ) questionnaire, standardized instrument, was used to measure the patients' perception of quality of nursing care. Section I consisted of demographic data and section II consisted of patients' perception of quality of nursing care which has 22 items on five point likert scale. The scoring level was interpreted as low quality nursing care $(<5 \%)$, adequate or good quality nursing care (50-75\%) and high quality nursing care $(>75 \%)$.

The original instrument in English was translated into Tamil and the reliability was obtained by using Spearman- Brown formula with value of .92. The data was analyzed using descriptive and inferential statistics.

\section{Results and Discussion:}

The results showed that the mean age of samples were 40.4 with standard deviation of (+) or (-) 20.49. Half of them $(50 \%)$ were males. Thirty four percent of patients were between the age group of 21-40 years ( 12 males and 5 females) and only $18 \%$ of them were adolescence $(<20$ years) ( 4 males and 5 females). Sixteen patients (32\%) were illiterate and 17 patients (34\%) were coolie. M ore than half of them (54\%) were stayed in the ward for 3-4 days and only $8(16 \%)$ were stayed for more than 5 days. Majority of the patients (80\%) had no history of previous hospitalization. M ost of the patients (88\%) rated quality of nursing care as positive and no one rated as negative.

Table 1 shows that the total mean score of patients' perception of quality of nursing care was 64.8 with standard deviation of $(+)$ or $(-)$ 13.2. This indicates that patients perception of quality of nursing care is adequate or good quality nursing care ( $80 \%)$. This was supported by the study results showed that overall mean score of patients' perception of quality of nursing care was high ${ }^{5,6}$

Table 2 reveals four dimensions of quality of nursing care such as providing information, concern and caring, skill and competency and management of patient. Eighteen patients (36\%) had perceived high quality in management of patient dimension and 35 (70\%) patients perceived good quality in concern and caring dimension. This was contradicted by the results of the study showed that $1 / 10^{\text {th }}$ (11.5\%) had poor perception on caring aspect. ${ }^{1}$ There were 19 (38\%) perceived low quality in the dimensions of providing information and skill and competency. This was supported by the results of the study revealed that almost $1 / 3$ patients (31.6\%) perceived that nurses did not offer adequate "explanation and information" about their treatment in hospital and home care and follow up advice. ${ }^{1}$

Table 3 reveals that association between patients'length of stay and perception of quality of nursing care and there were not statistically significant. But anotherstudy found a significant association with length of stay. ${ }^{1}$ 
Table 1 : M ean, standard deviation, frequency and percentage of overall patients' perception of quality of nursing care

\begin{tabular}{|l|c|c|c|c|c|}
\hline $\begin{array}{l}\text { Quality of } \\
\text { nursing care }\end{array}$ & $\begin{array}{c}\text { Percentage } \\
\text { of score }\end{array}$ & Frequency & $\begin{array}{c}\text { Percentage } \\
\text { of patients }\end{array}$ & M ean & $\begin{array}{c}\text { Standard } \\
\text { deviation }\end{array}$ \\
\cline { 1 - 4 } Low & $<50 \%$ & 6 & 12 & \multirow{2}{*}{64.8} & \multirow{2}{*}{13.2} \\
\cline { 1 - 4 } M oderate / good & $50-75 \%$ & 40 & 80 & & \\
\cline { 1 - 4 } high & $>75 \%$ & 4 & 8 & & \\
\hline
\end{tabular}

Table 2 : Frequency and percentage distribution of patients' perception of quality of nursing care in various dimensions among medical patients

\begin{tabular}{|c|l|c|c|c|c|c|c|}
\hline S.No & Dimensions of Quality & \multicolumn{2}{|c|}{ Low quality } & \multicolumn{2}{c|}{ Good quality } & \multicolumn{2}{|c|}{ High quality } \\
\hline & of nursing care & NO & $\%$ & NO & $\%$ & NO & $\%$ \\
\hline 1. & Provision of information & 19 & 38 & 28 & 56 & 3 & 6 \\
\hline 2 & Concern and Caring & 11 & 22 & 35 & 70 & 4 & 8 \\
\hline 3 & Skill and Competency & 19 & 38 & 23 & 46 & 8 & 16 \\
\hline 4 & Management of patient & 2 & 4 & 30 & 60 & 18 & 36 \\
\hline
\end{tabular}

Table 3 : Asso ciation between patients' length of stay and their perception of quality of nursing care.

\begin{tabular}{|l|c|c|c|c|}
\hline Length of stay & low quality & $\begin{array}{c}\text { M oderate/ Good } \\
\text { quality }\end{array}$ & High quality & $\begin{array}{c}\text { Chi- square } \\
\text { value }\end{array}$ \\
\hline$<5$ days & 4 & 35 & 3 & $\begin{array}{c}X^{2}-4.27 \\
\text { DF- } 2 \text { (NS) } \\
\text { P value - 5.99 }\end{array}$ \\
\hline$>5$ days & 2 & 5 & 1 &
\end{tabular}

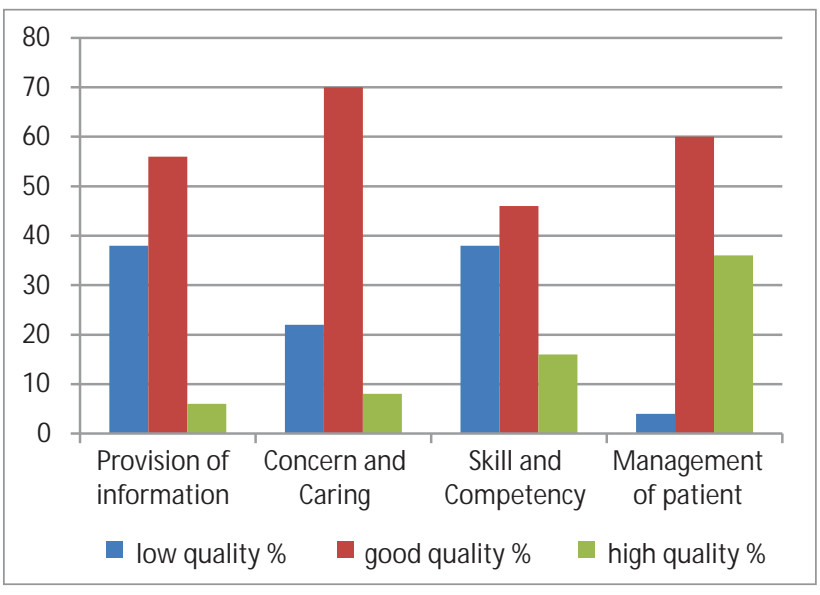

Fig 1 : Frequency and percentage distribution of patients' perception of quality of nursing care in various dimensions among medical patients

\section{Conclusion:}

This study gives valuable insight into patients' perception of overall aspect and various dimensions of quality of nursing care. The patients' perception of overall aspects of quality was good quality nursing care. Patients perceived high quality nursing care in the dimension of management of patient but they perceived low quality in the dimensions of providing information and skill and competency. Thus, nurses need to improve their skill and competency and update their knowledge by attending continuing nursing education programme and skill training workshops and provide information to the patients in order to improve patients' perception of quality of nursing care.

\section{Acknowledgements:}

We thank the management, principal, nursing superintendent, and staff of the concerned hospital for their cooperation and support.

\section{References:}

1. M ufti Samina, Qadri GJ, Tabish SA, Mufti Samiya, Riyaz R. Patient's perception of Nursing care at a large scale teaching hospital in India. International J ournal of Health Sciences. 2008 Jul;12(2):92-100.

2. Grandahl VA. Patient's perception of actual care conditions and patient satisfaction with care quality in hospital. Retrieved on $12^{\text {th }}$ oct 2013 . Available from: www.diva-portal.org/smash/get/diva 2:471271/FUயTEXT01

3. Bilkish NP, Sangita CS, Prakash A, Manjunath SK. A Cross sectional study of patient's satisfaction towards services received at tertiary care hospital on OPD basis. National journal of community medicine. 2012 Jun;3(2): 232-237.

4. Redfern S, Norman I. Quality of nursing care perceived by patients and their nurses: an application of the critical incident technique-part I. J ClinNurs. 1999 Jul;8(4):407-421.

5. Zhao SH, Akkadechanunt T,and Xue XL. Quality nursing care as perceived by nurses and patients in a Chinese hospital,Journal of Clinical Nursing 2009Jun;18(12):1722-8.

6. Lee MA \&Yom YH. A comparative study of patients' and nurses' perceptions of the quality of nursing services, satisfaction and intent to revisit the hospital: a questionnaire survey, International journal of Nursing Studies 2007 M ay; 44(4): 545-55. 